Research Paper

\title{
High Levels of Serum Adipocyte Fatty Acid-binding Protein Predict Cardiovascular Events in Coronary Artery Disease Patients
}

\author{
I-Ching Huang1, Bang-Gee Hsu ${ }^{1}$, 2 , Chao-Chien Chang ${ }^{1}$, Chung-Jen Lee ${ }^{3}$, Ji-Hung Wang ${ }^{1,4}$ \\ 1. School of Medicine, Tzu Chi University, Hualien, Taiwan \\ 2. Division of Nephrology, Buddhist Tzu Chi General Hospital, Hualien, Taiwan \\ 3. Department of Nursing, Tzu Chi University of Science and Technology, Hualien, Taiwan \\ 4. Division of Cardiology, Buddhist Tzu Chi General Hospital, Hualien, Taiwan \\ I-Ching Huang and Bang-Gee Hsu contributed equally to this study. \\ $\bowtie$ Corresponding author: abanggeelily@gmail.com; Tel.: +886-3-8561825 \\ (c) Ivyspring International Publisher. This is an open access article distributed under the terms of the Creative Commons Attribution (CC BY-NC) license \\ (https://creativecommons.org/licenses/by-nc/4.0/). See http://ivyspring.com/terms for full terms and conditions.
}

Received: 2018.02.17; Accepted: 2018.07.25; Published: 2018.08.06

\begin{abstract}
Background: Adipocyte fatty acid-binding protein (A-FABP) is a cardiometabolic predictor of cardiovascular (CV) disease in humans. We evaluated the association between serum A-FABP levels and future $C V$ events in patients with coronary artery disease (CAD).

Methods: $A$ total of 106 CAD patients were enrolled in this study between January and December 2012 and were followed-up until June 30, 2017. The primary endpoint was the incidence of major adverse CV events.

Results: During a median follow-up period of 53 months, $44 \mathrm{CV}$ events occurred. Patients with CV events presented higher systolic blood pressure $(p=0.020)$, total serum cholesterol $(p=0.047)$, and serum A-FABP levels $(p<0.001)$ compared with patients without $C V$ events. Kaplan-Meier analysis showed that the cumulative incidence of $C V$ events in the high A-FABP group (median A-FABP concentration of $>17.63 \mathrm{ng} / \mathrm{mL}$ ) was higher than that in the low A-FABP group (log-rank $p<0.001$ ). Multivariate Cox analysis showed that triglycerides (hazard ratio (HR): 1.008, 95\% confidence interval $(\mathrm{Cl})$ : 1.001-1.016, $\mathrm{p}=0.026$ ) and serum A-FABP levels (HR: 1.027, 95\% Cl: 1.009-1.047, $\mathrm{P}$ $=0.004$ ) were independently associated with CV events.
\end{abstract}

Conclusion: Serum A-FABP level is a biomarker for future CV events in patients with CAD. Further prospective studies are needed to confirm the mechanisms underlying this association.

Key words: Serum adipocyte fatty acid-binding protein, cardiovascular events, coronary artery disease patients

\section{Introduction}

Although the treatment of coronary artery disease (CAD) has undergone significant improvements, cardiovascular $(\mathrm{CV})$ events remain one of the leading causes of morbidity and mortality in the world [1]. Risk factors for CAD include hypertension, diabetes mellitus (DM), smoking, dyslipidemia, and obesity [2,3], which constitutes the most common risk factor for metabolic syndrome [3, 4]. Metabolic syndrome-a vital risk factor for $\mathrm{CV}$ disease - is independently associated with CAD [5].
Adipocyte fatty acid-binding protein (A-FABP) is abundantly found in mature adipocytes, activated macrophages, and dendritic cells [6, 7]. It belongs to a superfamily of small molecular weight lipid chaperones involved in lipid metabolism and metabolic and inflammatory responses and can accelerate $\mathrm{CV}$ disease [8]. A-FABP also contributes to atherosclerosis by increasing the formation of unstable carotid plaques $[8,9]$, and its inhibition has been shown to exert a protective effect against 
hyperglycemia, insulin resistance, and dyslipidemia, and a particularly strong protective effect against both early- and advanced-stage atherosclerosis [4, 10]. Since CAD patients with metabolic syndrome show an increased risk of $\mathrm{CV}$ morbidity, we investigated the association between the levels of serum A-FABP and future major adverse $\mathrm{CV}$ events in patients with CAD.

\section{Materials and methods}

\section{Participants}

This study was approved by the Protection of the Human Subjects Institutional Review Board of Tzu Chi University and Hospital. Prior to the study, all participants provided a written informed consent. Study participants were recruited from the CV outpatient department of the Buddhist Tzu Chi General Hospital, Hualien, Taiwan, and the inclusion criterion was that they had CAD history. CAD was defined as $>50 \%$ stenosis in any segment, detected by coronary angiography, which was evaluated from the medical record. Exclusion criteria included acute infection, malignancy, acute heart failure at the time of blood sampling, or refusal to provide informed consent for the study. A total of 106 CAD participants were enrolled between January and December 2012. In the morning, following a resting period of at least $10 \mathrm{~min}$, all patients had the blood pressure measured by trained staff using standard mercury sphygmomanometers with appropriate cuff sizes. Systolic BP (SBP) and diastolic BP (DBP) were measured thrice at $5 \mathrm{~min}$ intervals, and the results were averaged for analysis. A level of SBP $\geq 140$ $\mathrm{mmHg}$ and/or DBP $\geq 90 \mathrm{mmHg}$ resulted in a hypertension diagnosis. Additionally, patients treated with antihypertensive drugs in the past 2 weeks were also diagnosed as hypertensive, according to the Eighth Joint National Committee (JNC 8) guideline. Patients were diagnosed with DM if their fasting plasma glucose was either $\geq 126 \mathrm{mg} / \mathrm{dL}$ or if they were using oral hypoglycemic medications or insulin [11]. The prevalence of metabolic syndrome was defined using the International Diabetes Federation definition.

\section{Anthropometric evaluation}

All patients had their body weight and height measured while wearing light clothing and no shoes. Measurements were rounded up to the nearest $0.5 \mathrm{~kg}$ and $0.5 \mathrm{~cm}$, respectively. Waist circumference was measured at the midpoint between the lowest ribs and the iliac crest while the patient stood with the hands on the hips. The body mass index (BMI) was calculated using the Quetelet's formula by dividing the weight $(\mathrm{kg})$ by the squared height $\left(\mathrm{m}^{2}\right)[5,12-14]$.

\section{Biochemical analyses}

After an $8 \mathrm{~h}$ overnight fast, $5 \mathrm{~mL}$ blood samples were collected and immediately centrifuged at $3000 \mathrm{~g}$ for $10 \mathrm{~min}$. Serum levels of blood urea nitrogen (BUN), creatinine, fasting glucose, total cholesterol $(\mathrm{TCH})$, triglycerides (TG), high-density lipoprotein cholesterol (HDL-C), and low-density lipoprotein cholesterol (LDL-C) were determined using an autoanalyzer (COBAS Integra 800, Roche Diagnostics, Basel, Switzerland) [5, 12-14]. Serum A-FABP levels (SPI-BIO, Montigny le Bretonneux, France) were determined using a commercially available enzyme immunoassay (EIA) [5, 12-14]. The estimated glomerular filtration rate (eGFR) was calculated through the Chronic Kidney Disease Epidemiology Collaboration (CKD-EPI) equation.

\section{Data collection and endpoint definition}

The primary endpoint was the incidence of major adverse CV events, including death from cardiovascular causes, cardiac arrest, myocardial infarction, stroke, nonfatal stroke or other arterial thrombotic events, and hospitalization due to cardiovascular conditions such as unstable or progressive angina or heart failure. The follow-up period (in months) was estimated based on the last hospital outpatient or inpatient record or telephone interview before June 30, 2017, whereas the event time (in months) corresponded to the time until occurrence of the first major adverse CV event. The follow-up was performed by a study nurse who was unaware of the baseline measurements of the participants and the study protocol.

\section{Statistical analysis}

All statistical analyses were performed using the Statistical Package for the Social Sciences (SPSS) version 19.0 (SPSS Inc., Chicago, IL, USA). The distribution pattern of the variables was checked using the Kolmogorov-Smirnov test. Normally distributed variables were expressed as means \pm standard deviation and comparisons between patients were performed using the Student's independent $t$-test (two-tailed). Non-normally distributed variables were expressed as medians and interquartile ranges, and comparisons between patients were performed using the Mann-Whitney U test (TG, fasting glucose, $\mathrm{BUN}$, creatinine, and A-FABP). Categorical data were analyzed using the Chi-square test. The event-free survival during the follow-up period based on the median A-FABP levels was estimated using Kaplan-Meier survival curves with a log-rank test. The factors associated with $\mathrm{CV}$ events were determined using univariate and multivariate Cox regression models, including all covariates. Because 
TG, fasting glucose, BUN, creatinine, and A-FABP levels were not normally distributed, they underwent base 10 logarithmic transformations to achieve normality. Clinical variables that correlated with serum A-FABP levels in patients with CAD were evaluated using univariate linear regression analysis and multivariate forward stepwise regression analysis. A level of $p<0.05$ was considered statistically significant.

\section{Results}

The clinical characteristics of the 106 CAD patients are presented in Table 1. Fifty-one patients (48.1\%) had DM and 84 (79.2\%) had hypertension. The high A-FABP group (median A-FABP level of $>17.63$ $\mathrm{ng} / \mathrm{mL})$ had higher waist circumference $(\mathrm{p}=0.017)$, serum TG, and creatinine levels $(p=0.006$ and $p=$ 0.013 , respectively) and a lower eGFR $(p=0.019)$ than the low A-FABP group. CAD patients who had metabolic syndrome had significantly higher serum A-FABP levels than the levels of those without metabolic syndrome $(p=0.018)$.

The median follow-up period was 53 months, during which 44 major adverse CV events occurred. CAD patients undergoing major adverse $\mathrm{CV}$ events presented higher SBP $(p=0.020)$ and serum TCH and A-FABP levels $(p=0.047, p<0.001$, respectively) compared with those who did not experience major adverse CV events. No significant differences were found between groups concerning the patients' sex and comorbidity with DM or hypertension (Table 2).
The Kaplan-Meier analysis showed that the cumulative incidence of $\mathrm{CV}$ events in the high A-FABP group (median leptin concentration of $>17.63$ $\mathrm{ng} / \mathrm{mL}$ ) was higher than that in the low A-FABP group (log-rank $p<0.001$ ) (Figure 1$)$. The univariate Cox regression analysis showed that SBP (hazard ratio (HR): 1.018, 95\% confidence interval (CI): $1.003-1.033, \mathrm{p}=0.018$ ), TCH (HR: $1.009,95 \% \mathrm{CI}$ : $1.000-1.019, \mathrm{p}=0.048$ ), TG (HR: 1.003, 95\% CI: 1.000-1.005, $\mathrm{p}=0.023$ ), and serum A-FABP level (HR: 1.025, 95\% CI: 1.014-1.036, p < 0.001) were positively correlated with the occurrence of CV events, whereas the multivariate Cox analysis showed that TG (HR: 1.008, 95\% CI: 1.001-1.016, $\mathrm{p}=0.026)$ and serum A-FABP level (HR: 1.027, 95\% CI: 1.009-1.047, p = 0.004 ) were independently associated with the occurrence of CV events (Table 3).

The univariate linear analysis revealed that waist circumference $(\mathrm{r}=0.206, \mathrm{p}=0.034)$, systolic blood pressure $(\mathrm{r}=0.226, \mathrm{p}=0.020)$, logarithmically transformed triglyceride $(\log -\mathrm{TG}, \mathrm{r}=0.312, \mathrm{p}=0.001)$, and log-creatinine $(\mathrm{r}=0.244, \mathrm{p}=0.012)$ positively correlated, whereas eGFR $(r=-0.226, p=0.020)$ negatively correlated with serum log-A-FABP levels in patients with CAD. Multivariate forward stepwise linear regression analysis revealed that log-TG (adjusted $\mathrm{R}^{2}$ change $=0.088 ; \mathrm{p}=0.001$ ) and log-creatinine (adjusted $\mathrm{R}^{2}$ change $=0.032 ; \mathrm{p}=0.032$ ) positively correlated with serum log-A-FABP levels in patients with CAD (Table 4).

Table 1. Clinical characteristics of the 106 coronary artery disease patients according to serum adipocyte fatty acid-binding protein levels.

\begin{tabular}{|c|c|c|c|c|}
\hline Variables & All participants $(n=106)$ & Low A-FABP group $(n=53)$ & High A-FABP group $(n=53)$ & $\mathrm{p}$ value \\
\hline Age (years) & $65.66 \pm 8.68$ & $66.11 \pm 8.32$ & $65.21 \pm 9.08$ & 0.594 \\
\hline Height $(\mathrm{cm})$ & $161.80 \pm 7.42$ & $161.94 \pm 7.44$ & $161.66 \pm 7.46$ & 0.845 \\
\hline Body weight $(\mathrm{kg})$ & $68.39 \pm 11.95$ & $66.87 \pm 11.69$ & $69.92 \pm 12.13$ & 0.190 \\
\hline Waist circumference $(\mathrm{cm})$ & $92.83 \pm 9.87$ & $90.55 \pm 9.84$ & $95.11 \pm 9.45$ & $0.017^{*}$ \\
\hline Body mass index $\left(\mathrm{kg} / \mathrm{m}^{2}\right)$ & $26.00 \pm 3.36$ & $25.42 \pm 3.59$ & $26.59 \pm 3.02$ & 0.074 \\
\hline Systolic blood pressure $(\mathrm{mmHg})$ & $131.57 \pm 18.38$ & $128.13 \pm 15.36$ & $135.00 \pm 20.55$ & 0.054 \\
\hline Diastolic blood pressure (mmHg) & $72.08 \pm 9.81$ & $71.70 \pm 8.86$ & $72.45 \pm 10.75$ & 0.694 \\
\hline Total cholesterol (mg/dL) & $163.35 \pm 32.78$ & $159.72 \pm 31.15$ & $166.98 \pm 34.25$ & 0.256 \\
\hline Triglycerides (mg/dL) & $120.00(89.75-162.50)$ & $105.00(77.50-149.00)$ & $140.00(94.50-197.00)$ & $0.006^{*}$ \\
\hline HDL-C (mg/dL) & $44.80 \pm 12.10$ & $46.08 \pm 13.51$ & $43.53 \pm 10.47$ & 0.281 \\
\hline LDL-C (mg/dL) & $94.67 \pm 25.97$ & $92.06 \pm 25.82$ & $97.28 \pm 26.10$ & 0.302 \\
\hline Fasting glucose $(\mathrm{mg} / \mathrm{dL})$ & $111.00(95.75-139.75)$ & $106.00(93.50-140.50)$ & $111.00(97.50-147.00)$ & 0.340 \\
\hline Blood urea nitrogen $(\mathrm{mg} / \mathrm{dL})$ & $16.00(13.00-19.00)$ & $16.00(13.00-18.00)$ & $16.00(13.00-20.00)$ & 0.434 \\
\hline Creatinine (mg/dL) & $1.10(0.90-1.30)$ & $1.00(0.80-1.20)$ & $1.10(0.90-1.45)$ & $0.013^{*}$ \\
\hline eGFR (mL/min) & $68.67 \pm 19.375$ & $73.04 \pm 17.02$ & $64.30 \pm 20.71$ & $0.019^{*}$ \\
\hline A-FABP $(\mathrm{ng} / \mathrm{mL})$ & $17.63(10.74-27.28)$ & $10.89(8.40-16.43)$ & $26.44(21.84-38.12)$ & $<0.001^{*}$ \\
\hline Female (\%) & $24(22.6)$ & $12(22.6)$ & $12(22.6)$ & 1.000 \\
\hline Diabetes (\%) & $51(48.1)$ & $23(43.4)$ & $28(52.8)$ & 0.331 \\
\hline Hypertension (\%) & $84(79.2)$ & $39(73.6)$ & $45(84.9)$ & 0.151 \\
\hline Metabolic syndrome (\%) & $62(58.5)$ & $25(47.2)$ & $37(69.8)$ & $0.018^{*}$ \\
\hline
\end{tabular}

Normally distributed continuous variables are expressed as means \pm standard deviation and compared by Student's t-test; Non-normally distributed continuous variables are expressed as medians and interquartile range and compared by Mann-Whitney U test; Categorical variables are expressed as number (\%) and were analyzed using the chi-square test.

HDL-C, high-density lipoprotein cholesterol; LDL-C, low-density lipoprotein cholesterol; eGFR, estimated glomerular filtration rate; A-FABP, adipocyte fatty acid-binding protein.

${ }^{*} \mathrm{p}<0.05$ was considered statistically significant. 
Table 2. Clinical characteristics of the 106 coronary artery disease patients with or without cardiovascular events.

\begin{tabular}{|c|c|c|c|}
\hline Variables & Participants without cardiovascular events $(n=62)$ & Participants with cardiovascular events $(n=44)$ & $\mathrm{p}$ value \\
\hline Age (years) & $66.19 \pm 8.67$ & $64.91 \pm 8.74$ & 0.455 \\
\hline Height $(\mathrm{cm})$ & $161.95 \pm 7.47$ & $161.59 \pm 7.42$ & 0.806 \\
\hline Body weight $(\mathrm{kg})$ & $68.13 \pm 12.10$ & $68.76 \pm 11.87$ & 0.789 \\
\hline Waist circumference $(\mathrm{cm})$ & $92.79 \pm 9.80$ & $92.89 \pm 10.09$ & 0.961 \\
\hline Body mass index $\left(\mathrm{kg} / \mathrm{m}^{2}\right)$ & $25.86 \pm 3.47$ & $26.21 \pm 3.22$ & 0.595 \\
\hline Systolic blood pressure $(\mathrm{mmHg})$ & $128.10 \pm 16.23$ & $136.45 \pm 20.24$ & $0.020^{*}$ \\
\hline Diastolic blood pressure $(\mathrm{mmHg})$ & $70.98 \pm 10.52$ & $73.61 \pm 8.60$ & 0.175 \\
\hline Total cholesterol (mg/dL) & $158.03 \pm 27.80$ & $170.84 \pm 37.82$ & $0.047^{*}$ \\
\hline Triglycerides (mg/dL) & $108.00(88.75-151.25)$ & $135.50(91.25-194.50)$ & 0.116 \\
\hline HDL-C (mg/dL) & $44.05 \pm 10.71$ & $45.86 \pm 13.88$ & 0.449 \\
\hline LDL-C (mg/dL) & $91.63 \pm 24.10$ & $98.95 \pm 28.11$ & 0.153 \\
\hline Fasting glucose $(\mathrm{mg} / \mathrm{dL})$ & $109.00(95.75-132.25)$ & $111.00(95.50-158.75)$ & 0.540 \\
\hline Blood urea nitrogen $(\mathrm{mg} / \mathrm{dL})$ & $16.00(14.00-18.25)$ & $15.50(13.00-20.00)$ & 0.827 \\
\hline Creatinine (mg/dL) & $1.10(0.90-1.30)$ & $1.00(0.90-1.36)$ & 0.689 \\
\hline eGFR (mL/min) & $67.62 \pm 18.03$ & $70.16 \pm 21.25$ & 0.509 \\
\hline A-FABP $(\mathrm{ng} / \mathrm{mL})$ & $14.53(8.88-21.17)$ & $25.03(15.60-38.24)$ & $<0.001^{*}$ \\
\hline Female $(\%)$ & $11(20.0)$ & $10(23.3)$ & 0.697 \\
\hline Diabetes (\%) & $24(43.6)$ & $23(53.5)$ & 0.333 \\
\hline Hypertension (\%) & $39(70.9)$ & $37(88.6)$ & 0.075 \\
\hline \multicolumn{4}{|c|}{$\begin{array}{l}\text { Normally distributed continuous variables are expressed as means } \pm \text { standard deviation and compared by Student's t-test; Non-normally distributed continuous variables } \\
\text { are expressed as medians and interquartile range and compared by Mann-Whitney U test; Categorical variables are expressed as number (\%) and were analyzed using the } \\
\text { chi-square test. }\end{array}$} \\
\hline
\end{tabular}

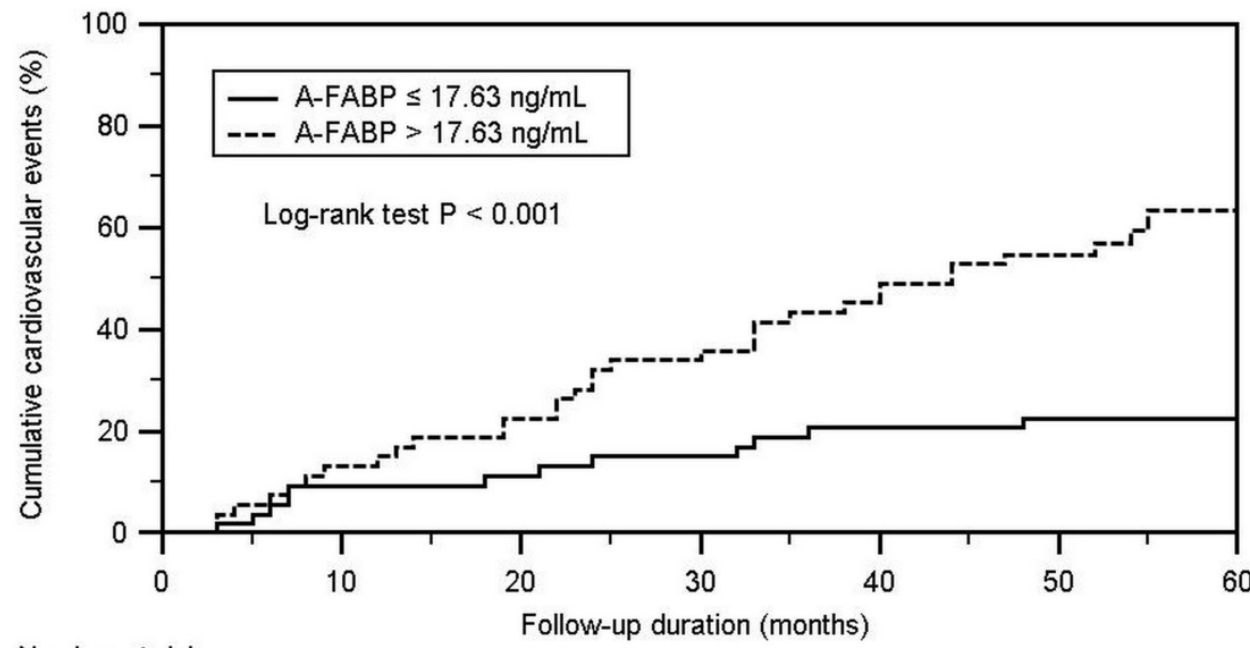

\begin{tabular}{|c|c|c|c|c|c|c|}
\hline $\begin{array}{l}\text { Number at ris } \\
\mathrm{A}-\mathrm{FABP} \leq 17\end{array}$ & & & & & & \\
\hline 53 & 48 & 47 & 45 & 42 & 39 & 0 \\
\hline $\mathrm{A}-\mathrm{FABP}>17$ & & & & & & \\
\hline 53 & 46 & 41 & 34 & 27 & 22 & 0 \\
\hline
\end{tabular}

Figure 1: Kaplan-Meier analysis according to adipocyte fatty acid-binding protein level for cardiovascular events in coronary artery disease.

Table 3. Cox regression of univariate and multivariate significant predictors of cardiovascular events among the 106 patients with coronary artery disease.

\begin{tabular}{|c|c|c|c|c|}
\hline \multirow[t]{2}{*}{ Variables } & \multicolumn{2}{|l|}{ Univariate } & \multicolumn{2}{|l|}{ Multivariate } \\
\hline & Hazard Ratio (95\% CI) & $\mathrm{p}$ value & Hazard Ratio (95\% CI) & $\mathrm{p}$ value \\
\hline Age (years) & $0.990(0.956-1.025)$ & 0.560 & - & - \\
\hline Height $(\mathrm{cm})$ & 0.999 (0.960-1.039) & 0.948 & - & - \\
\hline Body weight (kg) & $1.003(0.978-1.028)$ & 0.820 & - & - \\
\hline Waist circumference $(\mathrm{cm})$ & $1.001(0.972-1.032)$ & 0.937 & - & - \\
\hline Body mass index $\left(\mathrm{kg} / \mathrm{m}^{2}\right)$ & $1.016(0.930-1.110)$ & 0.722 & - & - \\
\hline Systolic blood pressure $(\mathrm{mmHg})$ & $1.018(1.003-1.033)$ & $0.018^{*}$ & - & - \\
\hline Diastolic blood pressure $(\mathrm{mmHg})$ & $1.022(0.992-1.053)$ & 0.157 & - & - \\
\hline Total cholesterol (mg/dL) & $1.009(1.000-1.019)$ & $0.048^{*}$ & - & - \\
\hline Triglycerides (mg/dL) & $1.003(1.000-1.005)$ & $0.023^{*}$ & $1.008(1.001-1.016)$ & $0.026^{*}$ \\
\hline HDL-C (mg/dL) & $1.009(0.985-1.035)$ & 0.455 & - & - \\
\hline LDL-C (mg/dL) & $1.008(0.996-1.020)$ & 0.178 & - & - \\
\hline
\end{tabular}




\begin{tabular}{|c|c|c|c|c|}
\hline \multirow[t]{2}{*}{ Variables } & \multicolumn{2}{|l|}{ Univariate } & \multicolumn{2}{|l|}{ Multivariate } \\
\hline & Hazard Ratio (95\% CI) & $\mathrm{p}$ value & Hazard Ratio (95\% CI) & $\mathrm{p}$ value \\
\hline Fasting glucose $(\mathrm{mg} / \mathrm{dL})$ & $1.002(0.997-1.007)$ & 0.524 & - & - \\
\hline Blood urea nitrogen $(\mathrm{mg} / \mathrm{dL})$ & $0.995(0.946-1.045)$ & 0.828 & - & - \\
\hline Creatinine (mg/dL) & $1.101(0.442-2.747)$ & 0.836 & - & - \\
\hline Glomerular filtration rate $(\mathrm{mL} / \mathrm{min})$ & $1.005(0.989-1.022)$ & 0.537 & - & - \\
\hline A-FABP (ng/mL) & $1.025(1.014-1.036)$ & $<0.001^{*}$ & $1.027(1.009-1.047)$ & $0.004^{*}$ \\
\hline Female $(\%)$ & $1.014(0.501-2.053)$ & 0.969 & - & - \\
\hline Diabetes $(\%)$ & $1.561(0.859-2.839)$ & 0.141 & - & - \\
\hline Hypertension (\%) & $1.851(0.782-4.382)$ & 0.155 & - & - \\
\hline
\end{tabular}

Univariate and multivariate Cox regression models were calculated to examine factors associated with cardiovascular events.

HDL-C, high-density lipoprotein cholesterol; LDL-C, low-density lipoprotein cholesterol; CI, confidence interval.

${ }^{*} \mathrm{p}<0.05$ was considered statistically significant.

Table 4. Correlation between serum adipocyte fatty acid-binding protein levels and clinical variables among 106 coronary artery disease patients.

\begin{tabular}{|c|c|c|c|c|c|}
\hline \multirow[t]{3}{*}{ Variables } & \multicolumn{5}{|c|}{ Log-A-FABP (ng/mL) } \\
\hline & \multicolumn{2}{|c|}{ Univariate } & \multicolumn{3}{|c|}{ Multivariate } \\
\hline & $\mathrm{r}$ & $\mathrm{p}$ value & Beta & $\begin{array}{l}\text { Adjusted } \\
\mathrm{R}^{2} \text { change }\end{array}$ & $\mathrm{p}$ value \\
\hline Age (years) & 0.026 & 0.794 & - & - & - \\
\hline Height $(\mathrm{cm})$ & -0.116 & 0.236 & - & - & - \\
\hline Body weight $(\mathrm{kg})$ & 0.055 & 0.578 & - & - & - \\
\hline Waist circumference $(\mathrm{cm})$ & 0.206 & $0.034^{*}$ & - & - & - \\
\hline Body mass index $\left(\mathrm{kg} / \mathrm{m}^{2}\right)$ & 0.143 & 0.144 & - & - & - \\
\hline Systolic blood pressure (mmHg) & 0.226 & $0.020^{*}$ & - & - & - \\
\hline $\begin{array}{l}\text { Diastolic blood pressure } \\
(\mathrm{mmHg})\end{array}$ & 0.077 & 0.431 & - & - & - \\
\hline Total cholesterol (mg/dL) & 0.087 & 0.374 & - & - & - \\
\hline Log-Triglycerides (mg/dL) & 0.312 & $0.001^{*}$ & 0.281 & 0.088 & $0.001^{*}$ \\
\hline HDL-C (mg/dL) & -0.148 & 0.129 & - & - & - \\
\hline LDL-C (mg/dL) & 0.039 & 0.689 & - & - & - \\
\hline Log-Glucose (mg/dL) & 0.100 & 0.307 & - & - & - \\
\hline Log-BUN (mg/dL) & 0.073 & 0.456 & - & - & - \\
\hline Log-Creatinine (mg/dL) & 0.244 & $0.012^{*}$ & 0.201 & 0.032 & $0.032^{*}$ \\
\hline eGFR (mL/min) & -0.226 & $0.020^{*}$ & - & - & - \\
\hline \multicolumn{6}{|c|}{$\begin{array}{l}\text { Data of triglyceride, fasting glucose, blood urea nitrogen, creatinine, and A-FABP } \\
\text { levels showed skewed distribution, and therefore were log-transformed before } \\
\text { analysis. }\end{array}$} \\
\hline $\begin{array}{l}\text { A-FABP, adipocyte fatty acid-bin } \\
\text { cholesterol; LDL-C, low density li }\end{array}$ & $\begin{array}{l}\text { ding } \mathrm{pr} \\
\text { lipoprot }\end{array}$ & $\begin{array}{l}\text { ein; HD } \\
\text { a choles }\end{array}$ & $\begin{array}{l}\text { high d } \\
\text { BUN, }\end{array}$ & sity lipo & $\begin{array}{l}\text { otein } \\
\text { hitrogen. }\end{array}$ \\
\hline
\end{tabular}

\section{Discussion}

This study showed that, among CAD patients, those who experience major $\mathrm{CV}$ events present higher fasting serum A-FABP levels than those who do not. Furthermore, serum TG and A-FABP level were independent predictors of $\mathrm{CV}$ events in patients with CAD.

A-FABP, also known as FABP4, is one of the most abundant components in mature adipocytes and belongs to a family of intracellular lipid chaperones [15]. It plays an important role in lipid oxidation and insulin sensitivity regulation. Several studies in mice report that A-FABP deficiency protects against hyperglycemia, insulin resistance, and dyslipidemia [16], and clinical studies show that serum A-FABP level is positively associated with the occurrence of metabolic syndrome [3, 10, 13, 17]. Both waist circumference and TG level are important risk factors for metabolic syndrome. In our study, the patients with higher serum A-FABP levels presented a higher waist circumference and serum TG level. Both critically ill sepsis patients and type 2 DM patients show a positive correlation between serum A-FABP concentration and serum creatinine $[13,17]$, and type 2 DM patients show a negative correlation between serum A-FABP and eGFR [17, 18]. Our results also showed that CAD patients who had metabolic syndrome had significantly higher serum A-FABP levels than the levels of those without metabolic syndrome and A-FABP levels were correlated positively with serum creatinine and negatively with eGFR.

CAD begins with atherosclerosis - an inflammatory process of the arteries' intima-and progresses into the narrowing of the coronary arteries' lumen [19]. The formation of an intraluminal coronary thrombus leads to symptomatic coronary occlusion and plaque rupture may cause fatal thrombotic events [20]. Elevated levels of TG or TG-rich lipoproteins and their remnants are increased risk factors for future $\mathrm{CV}$ events [21]. Possible mechanisms for this association include the production of proinflammatory mediators, such as free fatty acids and monoacylglycerols [22]. Our present findings also revealed that patients who developed a new $\mathrm{CV}$ event had significantly higher serum TG levels than those who did not. A-FABP is expressed in macrophages, and it induces foam cell formation as well as inflammatory responses via peroxisome proliferator-activated receptor gamma, IKB kinase and c-Jun NH2-terminal kinases, and activator protein-1 pathways [23, 24]. A-FABP influences inflammation and T-cell priming, and as a result, the carotid intima-media increases and the atherosclerotic plaque is formed [9]. In the epicardial adipose tissue, A-FABP promotes heart dysfunction by exerting a paracrine effect on cardiomyocytes, leading to a consequent heart remodeling and heart failure [25]. It also contributes to the development of neointima formation in the vascular endothelial cells, following vascular injury [26]. In vitro studies showed that A-FABP directly suppresses heart contraction in isolated adult rat cardiomyocytes [27]. Both clinical and experimental studies have reported a correlation 
between A-FABP and the occurrence of left ventricular hypertrophy and left ventricular systolic and diastolic dysfunction [10,28]. Clinical studies also revealed that serum A-FABP concentration is an outcome predictor of mortality in critically ill patients with sepsis, CV events in patients with stable angina undergoing percutaneous coronary intervention, and prognostic biomarker in patients with acute ischemic stroke [29-31]. Our study demonstrates that CAD patients with higher A-FABP had increased risk of $\mathrm{CV}$ events, after adjusting for other variables.

The present study had some limitations. First, this was a cross-sectional study, and further long-term prospective studies are needed to confirm the cause-effect relationship between the serum A-FABP level and the incidence of $C V$ events in CAD patients. Second, we used MACE to represent a group of diseases including $\mathrm{CV}$ diseases, thrombotic events, and cerebral vascular diseases. Further studies are necessary to analyze the causes of each disease and their incidence proportion. Third, in this study, medical interventions were not considered. Therefore, it cannot be excluded that some treatments or medications could have affected the incidence of $\mathrm{CV}$ events or influenced serum A-FABP levels [32, 33]. Further studies should be performed to confirm the relationship between A-FABP levels and CV outcome in CAD patients and to work on the prevention of $\mathrm{CV}$ diseases via this potential therapeutic target.

In conclusion, the present study showed that, in CAD patients, serum A-FABP levels are positively correlated with TG, waist circumference, and serum creatinine, and negatively correlated with eGFR. In addition, the serum A-FABP level is an important pathophysiological biomarker to future $\mathrm{CV}$ events in CAD patients.

\section{Abbreviations}

$\mathrm{CV}$ : cardiovascular; CAD: coronary artery disease; A-FABP: adipocyte fatty acid-binding protein; DM: diabetes mellitus; SBP: systolic blood pressure; DBP: diastolic blood pressure; BMI: body mass index; BUN: blood urea nitrogen; $\mathrm{TCH}$ : total cholesterol; TG: triglycerides; HDL-C: high-density lipoprotein cholesterol; LDL: and low-density lipoprotein cholesterol; eGFR: estimated glomerular filtration rate; CKD-EPI: chronic kidney disease epidemiology collaboration; HR: hazard ratio; CI: confidence interval.

\section{Acknowledgments}

This work was supported by grants from Tzu Chi Hospital (TCRD 101-03) in Taiwan.

\section{Competing Interests}

The authors have declared that no competing interest exists.

\section{References}

1. Krintus M, Kozinski M, Kubica J, Sypniewska G. Critical appraisal of inflammatory markers in cardiovascular risk stratification. Crit Rev Clin Lab Sci. 2014; 51: 263-79.

2. Brochu M, Poehlman ET, Ades PA. Obesity, body fat distribution, and coronary artery disease. J Cardiopulm Rehabil. 2000; 20: 96-108.

3. Xu A, Wang Y, Xu JY, Stejskal D, Tam S, Zhang J, et al. Adipocyte fatty acid-binding protein is a plasma biomarker closely associated with obesity and metabolic syndrome. Clin Chem. 2006; 52: 405-13.

4. von Eynatten M, Breitling LP, Roos M, Baumann M, Rothenbacher D, Brenner $\mathrm{H}$. Circulating adipocyte fatty acid-binding protein levels and cardiovascular morbidity and mortality in patients with coronary heart disease: A 10-year prospective study. Arterioscler Thromb Vasc Biol. 2012; 32: 2327-35.

5. Hsu BG, Chen YC, Lee RP, Lee CC, Lee CJ, Wang JH. Fasting serum level of fatty-acid binding protein 4 positively correlates with metabolic syndrome in patients with coronary artery disease. Circ J. 2010; 74: 327-31.

6. Makowski L, Boord JB, Maeda K, Babaev VR, Uysal KT, Morgan MA, et al. Lack of macrophage fatty-acid-binding protein aP2 protects mice deficient in apolipoprotein E against atherosclerosis. Nat Med. 2001; 7: 699-705.

7. Kralisch S, Fasshauer M. Adipocyte fatty acid binding protein: a novel adipokine involved in the pathogenesis of metabolic and vascular disease? Diabetologia 2013; 56: 10-21

8. Furuhashi M, Saitoh S, Shimamoto K, Miura T. Fatty acid-binding protein 4 (FABP4): Pathophysiological insights and potent clinical biomarker of metabolic and cardiovascular diseases. Clin Med Insights Cardiol. 2014; 8(Suppl 3): 23-33.

9. Rolph MS, Young TR, Shum BO, Gorgun CZ, Schmitz-Peiffer C, Ramshaw IA, et al. Regulation of dendritic cell function and $\mathrm{T}$ cell priming by the fatty acid-binding protein AP2. J Immunol. 2006; 177: 7794-801.

10. Rodríguez-Calvo R, Girona J, Alegret JM, Bosquet A, Ibarretxe D, Masana L. Role of the fatty acid-binding protein 4 in heart failure and cardiovascular disease. J Endocrinol. 2017; 233: R173-84.

11. Alberti KG, Zimmet PZ. Definition, diagnosis and classification of diabetes mellitus and its complications. Part 1: Diagnosis and classification of diabetes mellitus provisional report of a WHO consultation. Diabet Med. 1998; 15: 539-53.

12. Tsai JP, Wang JH, Lee CJ, Chen YC, Hsu BG. Positive correlation of serum adipocyte fatty acid binding protein levels with carotid-femoral pulse wave velocity in geriatric population. BMC Geriatr. 2015; 15: 88.

13. Huang IC, Chang CC, Lee CJ, Chen YC, Lee MC, Hsu BG. Positive correlation of serum adipocyte fatty acid binding protein levels with metabolic syndrome in kidney transplantation patients. Int J Clin Exp Pathol. 2017; 10: 8727-34

14. Chen MC, Hsu BG, Lee CJ, Yang CF, Wang JH. High serum adipocyte fatty acid binding protein level as a potential biomarker of aortic arterial stiffness in hypertensive patients with metabolic syndrome. Clin Chim Acta. 2017; 473: 166-72.

15. Makowski L, Hotamisligil GS. Fatty acid binding proteins-the evolutionary crossroads of inflammatory and metabolic responses. J Nutr. 2004; 134: 2464S-8S.

16. Furuhashi M, Tuncman G, Görgün CZ, Makowski L, Atsumi G, Vaillancourt $\mathrm{E}$, et al. Treatment of diabetes and atherosclerosis by inhibiting fatty-acid-binding protein aP2. Nature 2007; 447: 959-65.

17. Li JC, Wu DA, Hou JS, Subeq YM, Chen HD, Hsu BG. High serum adipocyte fatty acid binding protein is associated with metabolic syndrome in patients with type 2 diabetes. J Diabetes Res. 2016; 2016: 8380279.

18. Toruner F, Altinova AE, Akturk M, Kaya M, Arslan E, Bukan N, et al. The relationship between adipocyte fatty acid binding protein-4, retinol binding protein-4 levels and early diabetic nephropathy in patients with type 2 diabetes. Diabetes Res Clin Pract. 2011; 91: 203-7.

19. Wang JC, Normand SL, Mauri L, Kuntz RE. Coronary artery spatial distribution of acute myocardial infarction occlusions. Circulation 2004; 110: 278-84

20. Falk E, Nakano M, Bentzon JF, Finn AV, Virmani R. Update on acute coronary syndromes: the pathologists' view. Eur Heart J. 2013; 34: 719-28.

21. Reiner Ž. Hypertriglyceridaemia and risk of coronary artery disease. Nat Rev Cardiol. 2017; 14: 401-11.

22. Shapiro MD, Fazio S. From lipids to inflammation: New approaches to reducing atherosclerotic risk. Circ Res. 2016; 118: 732-49.

23. Makowski L, Brittingham KC, Reynolds JM, Suttles J, Hotamisligil GS. The fatty acid-binding protein, aP2, coordinates macrophage cholesterol trafficking and inflammatory activity. Macrophage expression of aP2 impacts peroxisome proliferator-activated receptor gamma and IkappaB kinase activities. J Biol Chem. 2005; 280: 12888-95.

24. Hui X, Li H, Zhou Z, Lam KS, Xiao Y, Wu D, et al. Adipocyte fatty acid-binding protein modulates inflammatory responses in macrophages 
through a positive feedback loop involving c-Jun NH2-terminal kinases and activator protein-1. J Biol Chem. 2010; 285: 10273-80.

25. Furuhashi M, Fuseya T, Murata M, Hoshina K, Ishimura S, Mita T, et al. Local production of fatty acid-binding protein 4 in epicardial/perivascular fat and macrophages is linked to coronary atherosclerosis. Arterioscler Thromb Vasc Biol. 2016; 36: 825-34.

26. Fuseya T, Furuhashi M, Matsumoto M, Watanabe $Y$, Hoshina K, Mita T, et al Ectopic fatty acid-binding protein 4 expression in the vascular endothelium is involved in neointima formation after vascular injury. J Am Heart Assoc. 2017; 6, e006377.

27. Lamounier-Zepter V, Look C, Schunck WH, Schlottmann I, Woischwill C, Bornstein SR, et al. Interaction of epoxyeicosatrienoic acids and adipocyte fatty acid-binding protein in the modulation of cardiomyocyte contractility. Int J Obes. 2015; 39: 755-61.

28. Fuseya T, Furuhashi M, Yuda S, Muranaka A, Kawamukai M, Mita T, et al. Elevation of circulating fatty acid-binding protein 4 is independently associated with left ventricular diastolic dysfunction in a general population. Cardiovasc Diabetol. 2014; 13: 126

29. Huang CL, Wu YW, Hsieh AR, Hung YH, Chen WJ, Yang WS. Serum adipocyte fatty acid-binding protein levels in patients with critical illness are associated with insulin resistance and predict mortality. Crit Care. 2013; 17: R22.

30. Takagi W, Miyoshi T, Doi M, Okawa K, Nosaka K, Nishibe T, et al. Circulating adipocyte fatty acid-binding protein is a predictor of cardiovascular events in patients with stable angina undergoing percutaneous coronary intervention. BMC Cardiovasc Disord. 2017; 17: 258.

31. Tu WJ, Zeng XW, Deng A, Zhao SJ, Luo DZ, Ma GZ, et al. Circulating FABP4 (fatty acid-binding protein 4) is a novel prognostic biomarker in patients with acute ischemic stroke. Stroke 2017; 48: 1531-8.

32. Miyoshi T, Doi M, Hirohata S, Kamikawa S, Usui S, Ogawa H, et al. Olmesartan reduces arterial stiffness and serum adipocyte fatty acid-binding protein in hypertensive patients. Heart Vessels. 2011; 26: 408-13.

33. Furuhashi M, Hiramitsu S, Mita T, Fuseya T, Ishimura S, Omori A, et al. Reduction of serum FABP4 level by sitagliptin, a DPP-4 inhibitor, in patients with type 2 diabetes mellitus. J Lipid Res. 2015; 56: 2372-80. 